\title{
Amplified Fragment Length Polymorphism Analysis Provides Strategies for Improvement of Bitter Gourd (Momordica charantia L.)
}

\author{
Ambika B. Gaikwad \\ National Research Centre on DNA Fingerprinting, National Bureau of Plant \\ Genetic Resources, Pusa Campus, New Delhi 110 012, India
}

Tusar Kanti Behera ${ }^{1,2}$, Anand K. Singh, and Devanshi Chandel

Indian Agricultural Research Institute, Pusa Campus, New Delhi 110 012, India

\author{
Jawahir L. Karihaloo \\ Asia-Pacific Consortium on Agricultural Biotechnology, NASC Complex, \\ Pusa Campus, New Delhi 110 012, India
}

Jack E. Staub

USDA-ARS, Vegetable Crops Unit, Department of Horticulture, 1575 Linden Drive, University of Wisconsin, Madison, WI 53706

Additional index words. bitter melon, molecular markers, breeding strategy, diversity

Abstract. Monoecious bitter gourd (Momordica charantia L. var. minima and maxima Williams \& Ng), a cucurbit of major economic importance, is widely cultivated in India, China, Africa, and South America. Although the morphology (i.e., growth habit and fruit shape, size, color, and surface texture) of Indian bitter gourd is diverse and gynoecious sex forms exist, a comprehensive diversity assessment of ecotypes has not been performed. Therefore, the genetic relatedness of 38 Indian cultigens (commercial varieties and cultivated landraces originating from different agroecological zones) was determined by amplified fragment length polymorphism (AFLP) analysis. Six primer combinations yielded a total of 519 bands of which $404(77.8 \%)$ were polymorphic among the cultigens examined. Unweighted pair group cluster analyses were performed using Jaccard's genetic similarities to define genetic relationships among cultigens. Genetic similarities among cultigens ranged between 0.44 and 0.88 , indicating that the bitter gourd cultigens examined were genetically diverse. Moreover, putative AFLP loci defined genetic relationships that allowed for partitioning of cultigens into two distinct groups [Group 1 and Group II (node 1); bootstrap = 100\%] after cluster analysis. With rare exception, cultigens were grouped with respect to geographical region, in which cultigens within a group and subgroups possessed high degrees of genetic similarity. The relatively high marker indices $(6.2$ to 19.4$)$, polymorphic information content of the markers used $(0.20$ to 0.25$)$, and multiplex ratios $(28.9$ to 77.4$)$ collectively indicate that the AFLP markers used are discriminatory in bitter gourd and that the analysis of the broad-based cultigens described provides valuable baseline information for advancing initial breeding strategies for this crop species.

Momordica charantia L. (Syn. bitter gourd, balsam pear, bitter melon, bitter cucumber, and African cucumber; $2 \mathrm{n}=22$ ) is a member of the family Cucurbitaceae, subfamily Cucurbitoideae, tribe Joliffieae, and subtribe Thladianthinae (Jeffrey, 1980). The word Momordica is derived from the Latin "mordeo," meaning "to bite," and is

\footnotetext{
Received for publication 29 June 2007. Accepted for publication 11 Sept. 2007.

${ }^{1}$ Current address: Division of Vegetable Science, Indian Agricultural Research Institute, New Delhi 110012 , India.

${ }^{2}$ To whom reprint requests should be addressed; e-mail behera@wisc.edu, tusar@rediffmail.com
}

descriptive of the bitter taste of all $\approx 40$ species in this Old World genus. Its domesticated and semidomesticated or wild progenitor types are listed in floras of tropical Africa, Asia (including India) as well as the New World tropics (Marr et al., 2004). More anciently, wild or small-fruited cultivated forms have been described in Indo-Aryan Ayurvedic texts written in Sanskrit during 2000 to $200 \mathrm{BC}$, indicating their relatively early $(<1590 \quad \mathrm{AD})$ cultivation in India (Decker-Walters, 1999). In fact, Indo-Aryan words for $M$. charantia may have been drawn from Dravidian culture (3000 BC to $2000 \mathrm{BC}$ ), which were present before the accent of the Indo-Aryan society, indicating an extremely ancient awareness of this plant species
(Decker-Walters, 1999). The morphologically diverse bitter gourd is one of the economically important and most widely grown vegetables in tropical regions where it varies in mature fruit size, color, surface texture, and edible maturity (Robinson and Decker-Walters, 1999) and also sex expression (i.e., monoecious and gynoecious sex types) (Behera et al., 2006). Although the general chemical composition of immature $M$. charantia fruit is similar to other cucurbit species, it is comparatively high in ascorbic acid and iron content making it an important food source for improved human health in the countries of its habitation (Behera, 2004).

Plant genetic erosion (genetic diversity reduction) has been hastened by urban encroachment of agricultural lands and rapid displacement of old varieties and landraces with improved cultivars during efforts to increase production (Harlan, 1975). India being a center of diversity of $M$. charantia, cultivated landraces and cultivars, i.e., cultigens, are grown ubiquitously on the countryside in rural agricultural areas. Recently, phenotypic- and DNA marker-based [random amplified polymorphic DNA (RAPD); Dey et al., (2006) and intersimple sequence repeat (ISSR); Singh et al., (2007) markers] diversity analyses of Indian $M$. charantia cultigens of diverse geographic origins were conducted to determine their population structure and genetic relationships. Genetic affinities among cultigens were evident from their geographic origin suggesting possibility of further expansion of existing Indian germplasm collection.

The RAPD and ISSR markers used by Dey et al. (2006) and Singh et al. (2007) for diversity assessment of bitter gourd, however, could not give complete insight into the cultigens examined. The discriminatory power of amplified fragment length polymorphism (AFLP) is often found to be greater than that of RAPD and ISSR markers (Powell et al., 1996; Vos et al., 1995) as a result of its highly polymorphic nature, wide dispersal throughout the genome, and comparatively high multiplex ratio (Milbourne et al., 1997). In cucurbits, AFLP diversity analysis has proven effective in discriminating closely related germplasm [water melon (Levi et al., 2004), melons (Garcia-Mas et al., 2000; Yashiro et al., 2005), Cucurbita pepo (Ferriol et al., 2003; Paris et al., 2003), Cucurbita moschata (Ferriol et al., 2004)]. Because AFLP-based genetic assessment of bitter gourd germplasm could further allow discrimination of genetic relationships of the cultigens examined by Singh et al. (2007), the present study was envisaged to characterize genetic relationships among previously described exotic (cultivated landraces) and elite (cultivars) Indian $M$. charantia cultigens using AFLP markers. Characterization of such AFLP marker profiles will provide baseline information for more extensive fingerprinting of common bitter gourd for use in plant variety protection, core collection development 
strategies, and the analysis of unadapted germplasm for use in plant improvement.

\section{Materials and Methods}

Plant materials. Based on fruit size, shape, color, and surface texture, M. charantia has been partitioned into two botanical varieties, which are widely cultivated in India: 1) var. charantia (cultivated form), which possesses large, nontapering (at either blossom or stem ends) fusiform fruits having numerous triangular tubercles; and 2) var. muricata (wild form), which produces small and round fruits with obvious tubercles that taper at both blossom and stem ends (Chakravarty, 1990). More recently, Reyes et al. (1994) reclassified Indian and Southeast Asian M. charantia botanical varieties based on fruit diameter [(M. charantia var. minima Williams $\& \mathrm{Ng})>5 \mathrm{~cm}$ and $M$. charantia var. maxima Williams \& $\mathrm{Ng}<5 \mathrm{~cm}]$. This latter classification was used in the present study. Thirty-eight indigenous cultigens of bitter gourd (M. charantia var. maxima and var. minima) comprising six genetically distinct, commercially released, agroecologically diverse varieties ('Pusa Do Mausami-green', 'CO 1', 'Priya', 'Preethi', 'MDU 1', and 'Arka Harit'; Table 1) and cultivated landraces, previously examined by RAPD and ISSR marker analysis (Singh et al., 2007), were raised at the Research Farm of the Indian Agricultural Research Institute, New Delhi, India, following recommendations of practice during February to June for drawing samples for AFLP evaluation. All these cultigens were self-pollinated at least four times before study.

Genomic DNA isolation. Genomic DNA was isolated from field-grown plants using the CTAB method (Doyle and Doyle, 1990).
Two grams of young leaves were ground into a fine powder using liquid nitrogen, suspended in $10 \mathrm{~mL}$ of homogenization buffer (100 mm Tris, pH 8, 20 mm EDTA, $1.4 \mathrm{M}$ $\mathrm{NaCl}, 2 \% \mathrm{CTAB}, 0.2 \%$ 2-mercaptoethanol), mixed by vortexing, and then incubated at $65{ }^{\circ} \mathrm{C}$ for $1 \mathrm{~h}$. The homogenate was then subjected twice to chloroform: isoamyl alcohol (24:1 by volume) extraction in which solutions underwent centrifugation for 15 min at $12,000 \mathrm{rpm}$ at $25{ }^{\circ} \mathrm{C}$. Total cellular DNA was subsequently precipitated with 0.6 volumes of isopropanol and pelleted by centrifugation at $15,000 \mathrm{rpm}$ for $20 \mathrm{~min}$. The recovered pellet was then washed with $70 \%$ ethanol, air-dried, and redissolved in TE buffer (Tris 10mm, EDTA $1 \mathrm{~mm}, \mathrm{pH} 8.0$ ). After RNAse treatment, the purified DNA was quantified using a fluorometer using a Hoechst dye (Hoefer, Inc., San Francisco, $\mathrm{CA})$, and then samples were diluted to

Table 1. Bitter gourd (Momordica charantia L.) accessions from India used for amplified fragment length polymorphism-based diversity analysis.

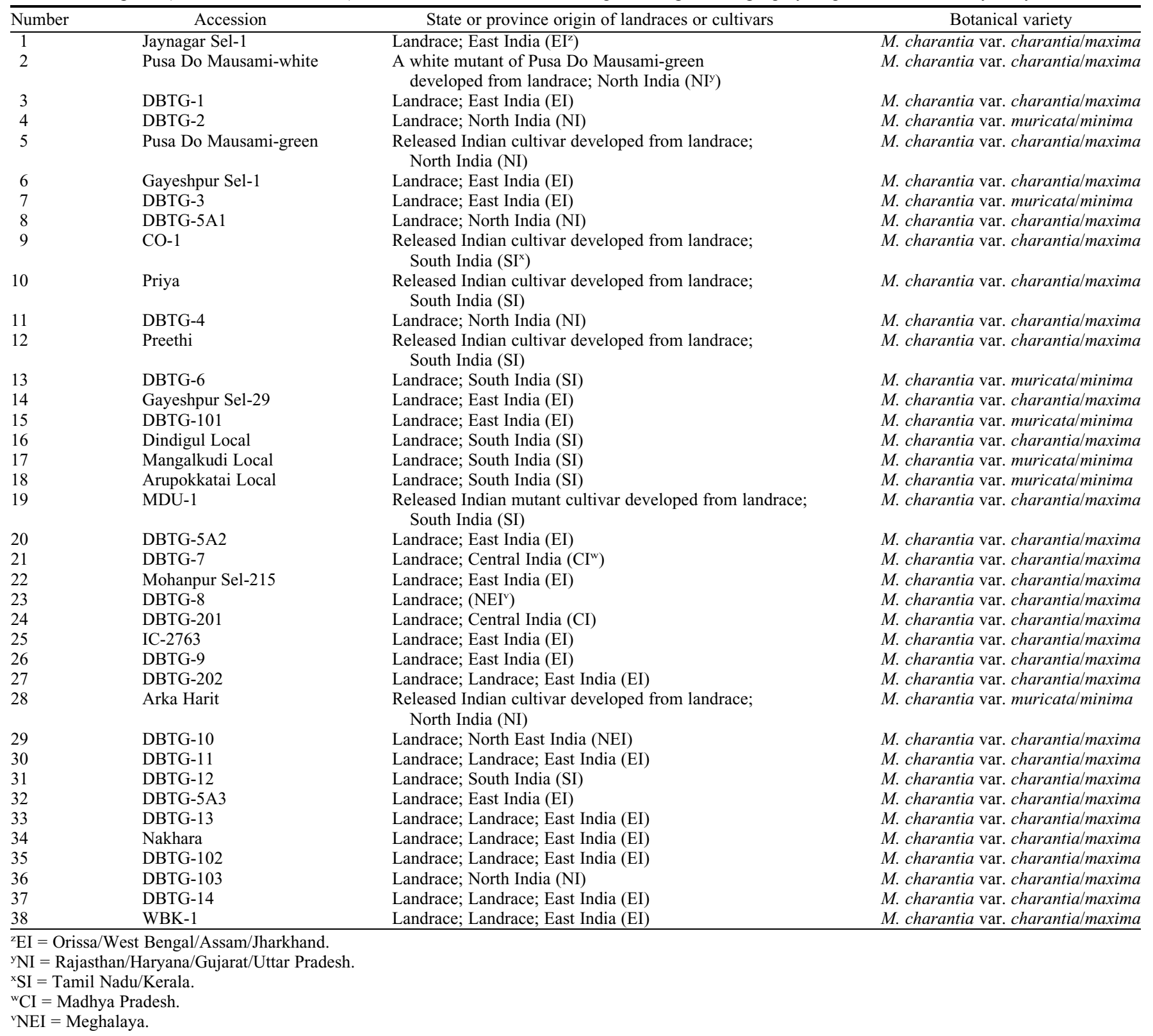


$25 \mathrm{ng} \cdot \mu \Lambda^{-1}$ before polymerase chain reaction amplification.

Amplified fragment length polymorphism analysis. The six primer combinations (designated as preselected) used in this investigation (Table 2) were selected because they showed a relatively high number of polymorphisms in an initial survey of 12 genetically diverse (as identified by Singh et al., 2007) bitter melon cultigens (data not using a Perkin Elmer Applied Biosystems fluorescent fragment detection kit (Plant Mapping Kit-Regular Plant Genome; Perkin Elmer Applied Biosystems, Foster City, CA). Genomic DNA (500 ng) was restricted with 5U EcoRI and 1U MseI (New England Biolabs, Beverly, MA) for $2 \mathrm{~h}$ at $37^{\circ} \mathrm{C}$. Ligation was then performed with respective adapters using T4 DNA ligase in a single reaction containing $1 \times \mathrm{T} 4 \mathrm{DNA}$ ligase buffer with ATP, $0.05 \mathrm{M} \mathrm{NaCl}, 0.5 \mu \mathrm{g}$ bovine serum albumin, and $1 \mu \mathrm{L}$ each of the EcoRI and MseI adapter pairs. Five microliters of diluted, restricted-ligated DNA was amplified using EcoRI and MseI preselective primers using the AFLP core mix supplied with the manufacturer's kit. The DNA was diluted 10 times and subjected to preselective amplification. The preselective amplification product of $25 \mu \mathrm{L}$ was used for multiplex selective amplification reactions using one nonfluorescent $M s e$ I primer and three EcoRI primers differentially labeled with three 5 ' fluorescent dyes (Perkin Elmer Applied Biosystems). The $2 \mu \mathrm{L}$ amplified product and 0.25 $\mu \mathrm{L}$ of the GENESCAN 500 ROX internal size standard (Perkin Elmer Applied Biosystems) were heat-denatured with $12 \mu \Lambda$ deionized formamide. Gel electrophoresis was conducted using a ABI Prism 310 genetic analyzer (Perkin Elmer Applied Biosystems) using an AFLP capillary system at $60^{\circ} \mathrm{C}$ for 30 min at $15 \mathrm{kV}$.

Data analyses. The fragment size of amplicons greater than a peak height of 100 were identified using ABI GENESCAN version 3.1 (Perkin Elmer Applied Biosystems), between 50 base pairs (bp) to 500 bp having unique mobilities were scored for band presence or absence using ABI GENOTYPER version 2.5 (Perkin Elmer Applied Biosystems). The NTSYS-pc software package shown). AFLP analyses were performed and distinct (bright), reproducible bands

version 2.02 (Rohlf, 1993) was used to calculate the Jaccard's similarity coefficients (Jaccard, 1908) between genotypes, and then dendrograms were constructed using an unweighted paired group method of arithmetic means (UPGMA) algorithm based on these similarity coefficients. The data were also subjected to bootstrap analyses to estimate the reliability of the clustering pattern. The FreeTree software package was used to perform bootstrap analyses (Pavlicek et al., 1999) to yield bootstrap values (based on 1000 resamplings), which defined major cluster groupings (Fig. 1).

Various primer and genetic population descriptors were calculated to define primer efficacy and to characterize differences among populations. The resolving power $(R p)$ of a primer was calculated as:

$$
R p=\sum I b,
$$

where $I b$ describes relative band informativeness and takes the value of: $1-[2 \times(0.5-p)]$, where $p=$ the proportion of the cultigens (38) possessing the band (Prevost and Wilkinson, 1999). Effective multiplex ratios (EMR) were calculated as the product of the proportion of polymorphic loci and the number of polymorphic loci (Milbourne et al., 1997). The average polymorphic information content $(P I C)$ and marker index $(M I)$ were calculated for each primer combination using the formula of Powell et al. (1996) and Smith et al. (1997) as:

$$
\mathrm{PIC}=1-\sum_{\mathrm{i}=1}^{\mathrm{n}} f_{i}^{2}
$$

where $f i$ is the frequency $(f)$ of the $i$ th allele. The PIC value provides an estimate of a marker's discriminatory power by accounting for the number and frequency of alleles at a given locus. Marker indices were calculated as the product of PIC and the number of polymorphic bands per assay unit (Lubberstedt et al., 2000). Unique marker bands (i.e., AFLP experimental unit) produced by each primer combination were considered genetically dominant for analysis. The average PIC value for each primer pair was obtained by averaging the PIC values for each marker band morphotype (absence or presence) scored. Likewise, MI was calculated as the

Table 2. Relative efficiency of six amplified fragment length polymorphism primer combinations applied to the diversity analysis of 38 bitter gourd (Momordica charantia L.) accessions.

\begin{tabular}{lccccccc}
\hline & $\begin{array}{c}\text { Total no. } \\
\text { Primer }\end{array}$ & $\begin{array}{c}\text { No. of } \\
\text { polymorphic } \\
\text { bands }\end{array}$ & $\begin{array}{c}\text { Polymorphism } \\
(\%)\end{array}$ & $\mathrm{EMR}^{\mathrm{z}}$ & $\mathrm{MI}^{\mathrm{z}}$ & $\mathrm{Rp}^{\mathrm{z}}$ & $\mathrm{PIC}^{\mathrm{z}}$ \\
\hline E-ACT/M-CTT & 40 & 34 & 85 & 28.9 & 6.02 & 12.41 & 0.21 \\
E-AAG/M-CTT & 110 & 88 & 80 & 70.4 & 16.60 & 38.04 & 0.24 \\
E-ACC/M-CTT & 107 & 91 & 85.0 & 77.4 & 19.35 & 38.99 & 0.25 \\
E-ACC/M-CAT & 57 & 43 & 75.4 & 32.4 & 6.34 & 15.15 & 0.20 \\
E-ACG/M-CAT & 115 & 79 & 68.7 & 54.3 & 11.03 & 33.31 & 0.20 \\
E-ACT/M-CAT & 90 & 69 & 76.7 & 52.9 & 11.15 & 27.25 & 0.21 \\
Total & 519 & 404 & - & - & - & - & - \\
Average & 86.5 & 67.3 & 78.5 & 52.7 & 11.75 & 27.52 & 0.22 \\
\hline
\end{tabular}

${ }^{\mathrm{z}} \mathrm{EMR}=$ effective multiplex ratio (Milbourne et al., 1997); $\mathrm{MI}=$ marker index (Powell et al., 1996); Rp = resolving power (Prevost and Wilkinson, 1999); PIC = polymorphic information content (Powell et al., 1996) (see "Materials and Methods" section). product of the number of polymorphic bands and corresponding PIC value per locus per primer pair.

The sum of polymorphic heterozygosity $\left(H_{p}\right)$ was calculated as the sum of the polymorphic information content for all loci for each primer pair $\left(H_{p}=\mathrm{PIC}\right)$, and the fraction of polymorphic loci $(\beta)$ is the number of polymorphic loci $\left(n_{p}\right)$ divided by the sum of polymorphic $\left(n_{p}\right)$ and nonpolymorphic loci $\left(n_{n p}\right)\left[\beta=n_{p} /\left(n_{p}+n_{n p}\right)\right]$ (Powell et al., 1996). The arithmetic mean heterozygosity $\left(H_{a v}\right)$ is the product of the polymorphic loci $(\beta)$ and the polymorphic heterozygosity $\left(H_{p}\right)$ divided by the number of polymorphic loci $\left(n_{p}\right)\left(H_{a v}=\beta \times H_{p} / n_{p}\right)$. The $E M R$ is defined as the product of the total number of loci per primer $(n)$ and the polymorphic loci $(\beta)$ $(\mathrm{EMR}=n \beta)$. The MI is the product of the total number of loci per primer pair (n) and the arithmetic mean heterozygosity $\left(H_{a v}\right)$ $\left(\mathrm{MI}=n H_{a v}\right)$.

\section{Results}

Primer combinations provided 519 fragments for analysis that ranged from 50 to $500 \mathrm{bp}$ (data not presented). The number of polymorphic fragments for each primer varied from 34 (E-ACT/M-CTT) to 91 (E-ACC/ $\mathrm{M}-\mathrm{CTT}$ ), and averaged 67 in the cultigens examined. Fragment number per individual primer pair averaged 86 and ranged from 43 (E-ACC/M-CAT) to 115 (E-ACG/M-CAT). Although the polymorphism level (polymorphic bands/total bands) ranged from $68.6 \%$ (E-ACG/M-CAT) to $85.04 \%$ (E-ACT/MCTT), the average polymorphism per primer combination was $77.8 \%$, and the primer MI ranged from 6.02 to 19.35 (Table 2). The largest MI value was obtained using primer pair E-ACC/M-CTT (19.35) followed by EAAG/M-CTT (16.60). The heterozygosity detected by the six primer pairs used ranged from 0.19 to 0.25 (data not presented), which paralleled the wide range of effective multiplex ratio values (28.9 to 77.4) (Table 2).

The discriminating power of each marker was estimated by PIC values that ranged between 0.20 and 0.25 (Table 2). Although the highest PIC value was detected using primer E-ACC/M-CTT (0.25), closely followed by E-AAG/M-CTT (0.24), a large proportion of the markers used exhibited almost similar discriminatory power. Similarity coefficient values ranged from 0.44 to 0.88 , in which the average Jaccard's similarity value among cultigens was 0.71 (data not presented). The UPGMA-derived cluster analysis revealed two groups (Group I and Group II) in which the bootstrap value was $100 \%$ indicative of complete support to the clustering event (Fig. 1). Group I contained four cultigens (' $\mathrm{CO}-1$ ', DBTG-5A3, DBTG$5 \mathrm{~A} 1$, and DBTG-3; node 1) that were distinctly different from the other cultigens examined (bootstra $p$ values ranged between $41 \%$ and $99 \%$ ). Group II was partitioned into five distinct subgroups (34 cultigens; subgroups $1-5$; node 2 to node 5 ), in which bootstrap values were more than $61 \%$. 


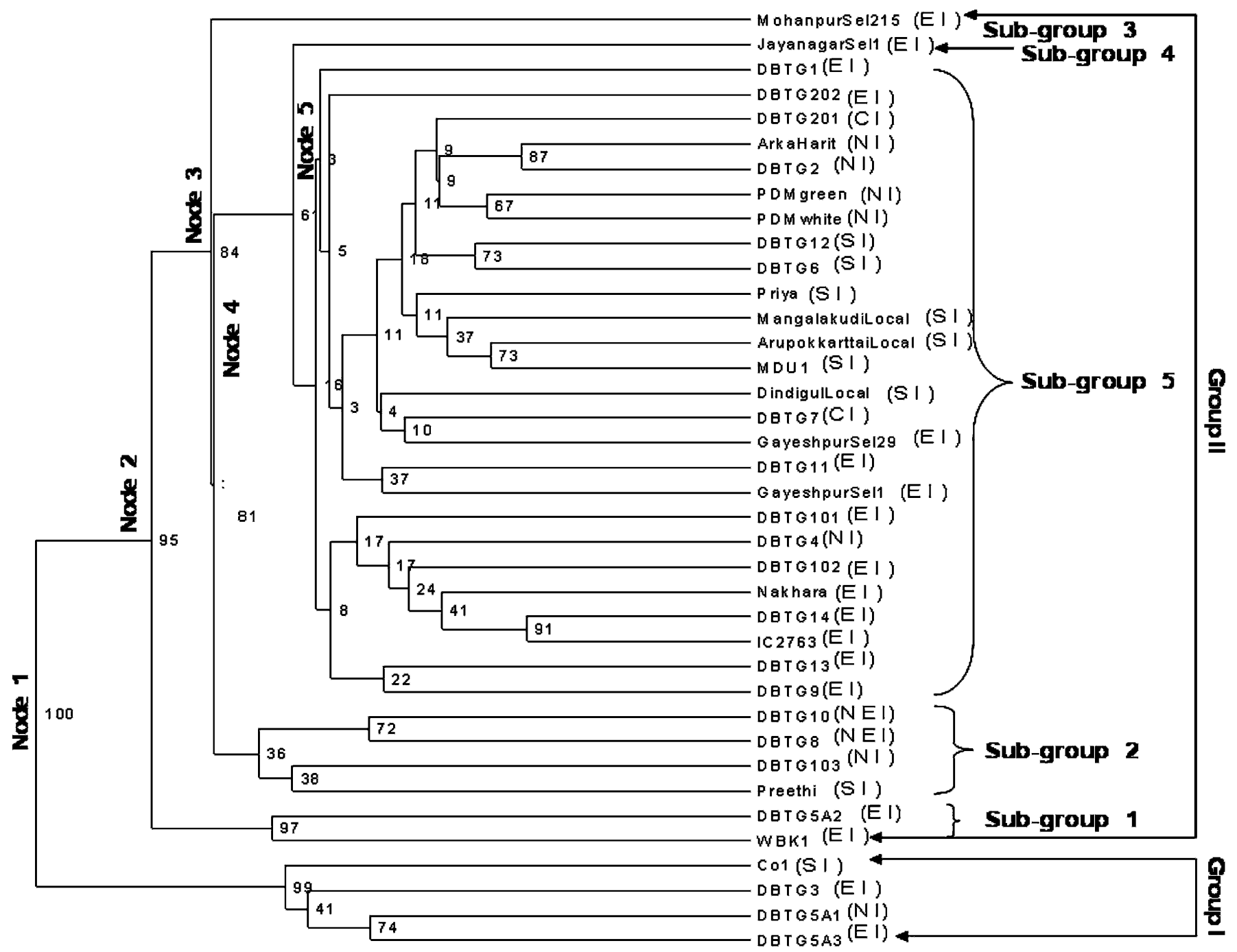

0.1

Fig. 1. Genetic relationships based on Jaccard's coefficient of similarity (Jaccard, 1908) after cluster analysis of Indian bitter gourd (Momordica charantia L.) accessions using 519 amplified fragment length polymorphism markers. Geographic origin of each accession is given in parentheses as EI = East India (Orissa/ West Bengal/Assam/Jharkhand); NI = North India (Rajasthan/Haryana/Gujarat/Uttar Pradesh); SI = South India (Tamil Nadu/Kerala); CI = Central India (Madhya Pradesh); and NEI = North East India (Meghalaya). The bootstrap values in percentages (based on a total of 1000 resamplings) for the four major clusters are given at the respective nodes. Cluster groupings are defined by the variation between and among accessions that support a bootstrap threshold value above 61 .

Although subgroup 1 of Group II contained two cultigens (WBK-1 and DBTG5A2; node 2), subgroup 2 consisted of four cultigens (DBTG-10, DBTG8, DBTG-101, and 'Preethi'; node 3), subgroup 3 contained only one cultigen (Mohanpur Sel-215; node 4), subgroup 4 also had one cultigen (Jayanagar Sel-1; node 5), and subgroup 5 housed the remaining cultigens ( 26 cultigens) (bootstrap values ranged between $3 \%$ and $91 \%$ ). Although cultigens in subgroup 5 were more diverse when compared with other subgroup clusters, bootstrap values associated with nodes within this subgroup were not particularly high (i.e., less that $40 \%$ ), and thus no attempt was made to partition this subgroup further. Within subgroup 5, several clusters were associated with relatively high bootstrap values ('Arka Harit' and DBTG-2, NI, bootstrap $=87 \%$; 'Pusa Do Mausami-green' and 'Pusa Do Mausami-white', NI, bootstrap $=67 \%$; DBTG-12 and DBTG-6, SI, bootstrap
=73\%; 'MDU-1' and Arrupkattai Local, SI, bootstrap $=73 \%$; DBTG-14 and IC-2763, EI, bootstrap $=91 \%)($ Fig. 1$)$, and most of the individuals within clusters were congruent with their sites of origin.

\section{Discussion}

Conservation of genetic resources is critical to plant breeding because economically important traits are constantly sought after to increase yield and quality and improve human health. Such genetic resources must be evaluated to allow for their effective and efficient use in plant improvement programs. The study reported in this article estimated genetic diversity among cultigens acquired from five uniquely different agroecological growing areas of India. Because identical cultigens were surveyed in a parallel study (Dey et al., 2006; Singh et al., 2007), direct comparisons could be made.
Marker efficiency and effectiveness. As expected, the bitter gourd cultigens examined in this study were genotypically different $(78.5 \%$ polymorphism) because they were drawn from distinctly different ecosystems and were morphologically dissimilar (Behera, 2004). Previous studies using RAPD and ISSR markers could not completely discriminate all of the bitter gourd cultigens examined (Dey et al., 2006; Singh et al., 2007). The AFLP analysis in this study, however, gave more complete dissection of unique differences among cultigens within and between collection sites.

The relative performance of marker types for genetic analysis varies among crop species. Russell et al. (1997) reported comparatively fewer polymorphic bands with AFLPs than with RAPDs (46.8\% versus $66.3 \%)$ in a survey of 18 cultivated barley accessions. We detected greater genetic diversity in bitter gourd from AFLP analysis compared with 
previous RAPD and ISSR analyses using the same germplasm array [(Dey et al., 2006) RAPD (36.5\%), (Singh et al., 2007), ISSR (74.5\%) polymorphisms]. Although the average polymorphic bands per AFLP primer combination were 67.3, detection of polymorphism per primer in RAPD (2.6; Dey et al., 2006) and ISSR (6.3; Singh et al., 2007) was drastically lower. Garcia-Mas et al. (2000) observed similar differences in polymorphism percentage when comparing AFLPs (23.1\%), restriction fragment length polymorphism (RFLP) (62\%), and RAPDs (18\%) markers in melon (Cucumis melo L.). In that study, polymorphisms detected per AFLP primer combination were, on average, higher (15.08 polymorphic bands) than that detected using RFLP (1.47) and RAPD (0.73) markers on a per-primer basis. The increased differentiation level witnessed was partly the result of the number and comparatively high discriminatory power of AFLP markers used as well as the diverse nature of the germplasm examined.

The types of DNA markers used to study the genetic diversity of bitter gourd [i.e. Dey et al., 2006 (RAPD), Singh et al., 2007 (ISSR), and AFLP present study] differ in the origin of character state and genomic distribution (Powell et al., 1996; Staub et al., 1996). Nevertheless, AFLP, RFLP, and RAPD genetic diversity assessments in Cucumis melo L. have been shown to be similar (Garcia-Mas et al., 2000; $\mathrm{r}^{2}=0.91$, AFLPs versus RAPDs), and broad-based analyses of Cucurbita pepo accessions using AFLP, ISSR, and simple sequence repeat (SSR) markers were highly correlated (Paris et al., 2003; $\mathrm{r}^{2}=0.95$, AFLPs versus ISSR). In contrast, a relatively low correlation $\left(\mathrm{r}^{2}=\right.$ 0.17 to 0.40 depending on the coefficient used) was detected between RAPD and SSR marker analyses during genetic diversity assessment of melon (Staub et al., 2000). The AFLP markers were, however, not correlated with previous ISSR $\left(\mathrm{r}^{2}=0.007\right)$, RAPD $\left(r^{2}=0.04\right)$, and ISSR + RAPD $\left(r^{2}=\right.$ $0.03)$ marker analyses performed on the identical cultigens. Noteworthy, however, was the comparatively high relationship $\left(\mathrm{r}^{2}=0.70\right)$ found between RAPD and ISSR marker systems suggesting similarities in their discriminatory nature in the cultigens examined. A primary reason for the low correlation between AFLP and RAPD or ISSR markers might be the result of the nature of the genetic differences detected among these systems (Belaj et al., 2003) and the number of primers used (comparatively higher number in RAPDs).

Allele frequency and number are used to estimate population polymorphism (Powell et al., 1996). Population heterozygosity can be characterized by marker genotype analysis, and, thus, quantitative approximations of marker usefulness are typically described by heterozygosity $\left(H_{p}\right.$ and $\left.H_{a v}\right)$ estimators and MI values (Table 2 ). The MI values derived from the six pairs of primers used differed greatly, indicating that they vary in their discriminatory power $(\mathrm{E}-\mathrm{ACC} / \mathrm{M}-\mathrm{CTT}>\mathrm{E}-$ AAG/M-CTT > E-ACT/M-CAT > E-ACG/
M-CAT). The average MI value among the 38 cultigens examined was 11.75 , which was mainly the result of the remarkably high average number of bands per lane (86.5). Relatively large MI values have also been reported in other crop species [maize (Lubberstedt et al., 2000; Pejic et al., 1998), barley (Russell et al., 1997), soybean (Powell et al., 1996)]. The comparatively high MI (19.35) derived from E-ACC/M-CTT in our study was mainly the result of the comparatively high number of polymorphic bands (90) generated. Thus, this primer pair might have value for the genotyping of bitter gourd lines being considered for plant variety protection or registration.

Germplasm characterization. The AFLPdefined relationships among the 38 different bitter melon cultigens (varieties and landraces) examined were congruent with differences in their agroecological growing environments, e.g., cultigen 'DBTG-2' and cultivar 'Arka Harit' originating from landraces in Rajasthan (northwest India) were clustered together (Fig. 1; subgroup 5; bootstrap value $87 \%$ ). Likewise, a white-fruited (exocarp) mutant, 'Pusa Do Mausami-white', and its green fruited counterpart, 'Pusa Do Mausami-green', having similar vegetative and reproductive morphology, were also grouped together (subgroup 5; bootstrap value $67 \%$ ). Cluster groupings from RAPD (Dey et al., 2006) and ISSR analyses (Singh et al., 2007) of the cultigens also used in the present study were not concordant with geographical origin or gross morphological differences between cultigens (varieties charantia/maxima vs. muricata/minima). Genotypes with contrasting morphological characters could, however, be used for testing specific genetic or physiological hypotheses. For instance, the mutant, 'Pusa Do Mausamiwhite', was derived from 'Pusa Do Mausamigreen' and these cultigens are very similar morphologically, except for a difference in exocarp color, which is conditioned by a single locus. Thus, these cultigens have value as parental stocks in mapping experiments in which fruit coloration and characterization of pigment biosynthesis pathways are important.

Botanical varieties charantia/maxima and muricata/minima have similar genetic affinities but display different morphological characteristics. The fruits of 'Pusa Do Mausami-green' (Momordica charantia var. charantia/maxima) are medium-sized (15 to $18 \mathrm{~cm}$ long weighing 80 to $100 \mathrm{~g}$ ), green, club-shaped, and have unbroken ridges with tubercles (raised surfaces) on the surface. In contrast, the cultivar 'Arka Harit' (Momordica charantia var. muricata/minima) bears small, spindle-shaped, glossy green fruit (10 to $12 \mathrm{~cm}$ long weighing 60 to $70 \mathrm{~g}$, respectively) without tubercles. These cultigens were grouped according to origin after cluster analysis (Fig. 1, Group I; subgroup 5) and were derived from similar landraces inhabiting distinctive agroecological growing environments ('Arka Harit', a popular cultivar of South India, and 'Pusa Do Mausami-green' of North India). These varieties probably responded differently to selection pressures imposed on them by their respective agroclimatic zones. In contrast, 'CO-1', 'Preethi', 'Priya', and 'MDU-1' originating in south India grouped in separate clusters [Fig. 1; 'CO-1' (Group I); 'Preethi' (Group II, subgroup 2), and 'Priya' and 'MDU-1' (Group II, subgroup 5)] were descended from local landraces in the same agroecological region (south India) but maintained genetic distinctions during domestication. These findings are in variation to those of Dey et al. (2006) and Singh et al. (2007) who did not report such observations.

Eastern India has been proposed as a center of domestication for bitter gourd (Yang and Walters, 1992). The most genetically diverse cultigens examined by us [Mohanpur Sel-215, Jayanagar Sel-1, DBTG-202 (syn. gynoecious line DBGy202)] originated from east India (Orissa, West Bengal, Jharkhand) and were relegated to unique subgroups (subgroup 3 and subgroup 5) after cluster analysis (Fig. 1). These relationship differences parallel the results of Dey et al. (2006; RAPD analysis) and Singh et al. (2007; ISSR analysis) who detected distinct genetic differences among Mohanpur Sel-215, Jayanagar Sel-1, and the remaining bitter gourd genotypes examined. The cultigens (Mohanpur Sel-215 and Jayanagar Sel1) are of considerable interest for genetic studies and plant improvement. They can be used as reference cultigens in future diversity analyses, considered as potential parents for map construction, and assessed for economically important traits for use in conventional or marker-assisted selection (MAS).

Standard monoecious bitter gourd accessions do not produce staminate flowers until vegetative or reproductive maturity (plants that have already produced several successive cycles of pistillate flowers) (Behera et al., 2006), and thus the staminate-to-pistillate flower sex ratio in this sex type is relatively high (9:1 to 48:1; Dey et al., 2005). This sex expression motif and the fact that flowers are extremely small (fully expanded corolla 10 to $15 \mathrm{~mm}$ in diameter) creates difficulty during commercial hybrid seed production. Two genetically distinct gynoecious (Gy) lines DBTG-201 (syn. DBGy-201) and DBTG202 (syn. DBGy-202) grouped together after cluster analysis (Table 1; Fig. 1; subgroup 5), confirming relationships detected in earlier studies (Dey et al., 2006; Singh et al., 2007). Like in cucumber (Cucumis sativus L.) (Staub and Bacher, 1997), the use of such gynoecious lines in hybrid production would increase the efficiency of hybrid seed production in bitter gourd by increasing earliness and flowering uniformity (Behera, 2004). The effective use of gynoecious lines for hybrid seed production would require an understanding of the inheritance of sex expression in bitter gourd followed by the strategic implementation of introgression backcrossing procedures to transfer the gene(s) for gynoecy into elite lines. The identification of marker arrays for detection of gynoecy in early stages of plant 
growth could also be useful for developing predominantly gynoecious cultivars in bitter gourd.

Genetic diversity assessment provides opportunities for enhancing curatorial management practices and allows for the characterization of unique cucurbit germplasm (Lebeda et al., 2007). Likewise, phenotypic and molecular characterization of exotic cucurbit germplasm defines their potential for broadening a species' germplasm base. Strategies for increasing genetic diversity include introgression from exotic cucurbit species (Chen et al., 2003), the development of hybrids using distant related plants as parents (Staub et al., 2005), and the exploitation of biotechnologies (transformation, embryo rescue in wide species introgression) (Wang et al., 2006). Our study provides a description of genetic relationships among promising cultigens originating from distinct geographic regions (i.e., Mohanpur Sel-215, Jayanagar Sel-1, DBTG-A1, DBTG-5A3, DBTG-201, DBTG-202, and 'Pusa Do Mausami-white'). These cultigens could be used directly as parents in hybridization for commercialization or as germplasm for selection to improve economically important traits (i.e., yield, predominantly gynoecious habit and fruit size). Selection among these cultigens can also be concurrently applied for improving medical attributes associated with bitter gourd's health-related benefits (diabetes, cancer, and HIV) (Basch et al., 2003; Lee-Huang et al., 1990, 1995). This would include breeding for increased levels of charantin, vicine, polypeptide-p, phenolics, polyphenolic compounds, and natural oxidants and antioxidants in seed and vegetative plant parts (Ahmed et al., 2001; Ali et al., 1993; Dutta et al., 1981; Ganguly et al., 2000; Grover et al., 2002; Horax et al., 2005; Jayasooriya et al., 2000; Krawinkel and Keding, 2006; Yeh et al., 2003).

The AFLP diversity assessment reported here provides additional markers for the establishment of a broad-based descriptive marker array (AFLP, ISSR, and RAPD) for improved germplasm curation and the identification of germplasm for genome mapping and breeding. Nevertheless, the effectiveness of this marker array could be enhanced (increased discriminatory power) by the development of AFLP markers that combine the speed of the RAPD technology with the precision of RFLP techniques (Powell et al., 1996; Vos et al., 1995). Such markers have been effective in the mapping of economically important traits in cucumber and their subsequent introgression by MAS (Fan et al., 2006; Fazio et al., 2003; Sun et al., 2006). Similarly, these discriminating marker arrays could also be rewarding for bitter gourd improvement by deriving mapping populations from genetically diverse cultigens emerging from this study.

\section{Literature Cited}

Ahmed, I., M.S. Lakani, M. Gillett, A. John, and H. Raza. 2001. Hypotriglycerimic and hypocholesterolemic effects of anti-diabetic Momord- ica charantia (karela) fruit extract in streptozotocin-induced diabetic rats. Diabetes Res. Clin. Pract. 51:155-161.

Ali, L., A.K.A. Khan, M.I.R. Mamun, M. Mosihzzaman, N. Nahar, M.N. Alam, and B. Rokey. 1993. Studies of hypoglycaemic effects of fruit pulp, seed and sole plant of Momordica charantia on normal and diabetic model rats. Planta Med. 59:408-412.

Basch, E., S. Gabardi, and C. Ulbricht. 2003. Bitter melon (Momordica charantia): A review of efficacy and safety. Amer. J. Health Syst. Pharm. 60:356-359.

Behera, T.K. 2004. Heterosis in bitter gourd, p. 217-221. In: P.K. Singh, S.K. Dasgupta, and S.K. Tripathi (eds.). Hybrid vegetable development. The Haworth Press, New York.

Behera, T.K., S.S. Dey, and P.S. Sirohi. 2006. 'DBGy-201' and 'DBGy-202': Two gynoecious lines in bitter gourd (Momordica charantia L.) isolated from indigenous source. Indian J. Genet. Plant Breed. 66:61-62.

Belaj, A., Z. Satovic, G. Cipriani, L. Baldoni, R. Testolin, L. Rallo, and I. Trujillo. 2003. Comparative study of the discriminating capacity of RAPD, AFLP and SSR markers and of their effectiveness in establishing genetic relationships in olive. Theor. Appl. Genet. 107: 736-744.

Chakravarty, H.L. 1990. Cucurbits of India and their role in the development of vegetable crops, p. 325-334. In: D.M. Bates, R.W. Robinson, and C. Jeffrey (eds.). Biology and utilization of cucurbitaceae. Cornell University Press, Ithaca, New York.

Chen, J.F., X.D. Luo, J.E. Staub, C.T. Qian, F.Y. Zhuang, and G. Ren. 2003. An allotriploid derived from an amphidiploid-diploid mating in Cucumis I: Production, micro-propagation and verification. Euphytica 131:235-241.

Decker-Walters, D.S. 1999. Cucurbits, Sanskrit, and the Indo-Aryans. Econ. Bot. 53:98-112.

Dey, S.S., T.K. Behera, A. Pal, and A.D. Munshi. 2005. Correlation and path coefficient analysis in bitter gourd (Momordica charantia L.). Veg. Sci. 32:173-176.

Dey, S.S., A.K. Singh, D. Chandel, and T.K. Behera. 2006. Genetic diversity of bitter gourd (Momordica charantia L.) genotypes revealed by RAPD markers and agronomic traits. Sci. Hort. 109:21-28.

Doyle, J.J. and J.L. Doyle. 1990. Isolation of plant DNA from fresh tissue. Focus 12:13-15.

Dutta, P.K., A.K. Chakravarty, and U.S. Chowdhary. 1981. Vicine, a favism-inducing toxin from Momordica charantia L. seeds. Indian J. Chem. 20:669-671.

Fan, Z., M.D. Robbins, and J.E. Staub. 2006. Population development by phenotypic selection with subsequent marker-assisted selection for line extraction in cucumber (Cucumis sativus L.). Theor. Appl. Genet. 112:843-855.

Fazio, G., S.M. Chung, and J.E. Staub. 2003. Comparative analysis of response to phenotypic and marker-assisted selection for multiple lateral branching in cucumber (Cucumis sativus L.). Theor. Appl. Genet. 107:875-883.

Ferriol, M., B. Pico, P.F. de Cordova, and F. Nuez. 2004. Molecular diversity of a germplasm collection of squash (Cucurbita moschata) determined by SRAP and AFLP markers. Crop Sci. 44:653-664.

Ferriol, M., B. Pico, and F. Nuez. 2003. Genetic diversity of a germplasm collection of Cucurbita pepo using SRAP and AFLP markers. Theor. Appl. Genet. 107:271-282.

Ganguly, C., S. De, and S. Das. 2000. Prevention carcinogen induced mouse skin papilloma by whole fruit aqueous extract of Momordica charantia. Eur. J. Cancer Prev. 9:283-288.

Garcia-Mas, J., M. Oliver, H. Gomez-Paniagua, and M.C. De Vicente. 2000. Comparing AFLP, RAPD and RFLP markers for measuring genetic diversity in melon. Theor. Appl. Genet. 101:860-864.

Grover, J.K., S. Yadav, and V. Vats. 2002. Medicinal plants of India with antidiabetic potential. J. Ethnopharmacol. 81:81-100.

Harlan, J.R. 1975. Our vanishing genetic resources. Science 188:618-621.

Horax, R., N. Hettiarachchy, and S. Islam. 2005. Total phenolic contents and phenolic acid constituents in 4 varieties of bitter melon (Momordica charantia) and antioxidant activities of their extracts. J. Food Sci. 70:275-280.

Jaccard, P. 1908. Nouvelles recherches sur la distribution florale. Bulletin de la Societé Vanddoise des Sciences Naturelles 44:223-270.

Jayasooriya, A.P., M. Sakono, C. Yukizaki, M. Kawano, K. Yamamoto, and N. Fukuda. 2000. Effects of Momordica charantia powder on serum glucose levels and various lipid parameters in rats fed with cholesterol-free and cholesterol-enriched diets. J. Ethnopharmacol. 72:331-336.

Jeffrey, C. 1980. A review of the cucurbitaceae. Bot. J. Linn. Soc. 81:233-247.

Krawinkel, M.B. and G.B. Keding. 2006. Bitter gourd (Momordica charantia): A dietary approach to hyperglycemia. Nutr. Rev. 64:331-337.

Lebeda, A., M.P. Widrlechner, J.E. Staub, H. Ezura, J. Zalapa, and E. Krístková. 2007. Cucurbits (Cucurbitaceae; Cucumis spp., Cucurbita spp., Citrullus spp.), p. 271-376. In: R.J. Singh (ed.). Genetic resources, chromosome engineering, and crop improvement, Vol. 3. CRC Press, Boca Raton, FL.

Lee-Huang, S., P.L. Huang, A.S. Bourinbaiar, H.C. Chen, and H.F. Kung. 1995. Inhibition of integrate of human immuno-deficiency virus (HIV) type 1 by anti-HIV plant proteins MAP30 and GAP31. Proc. Natl. Acad. Sci. USA 92:8818-8822.

Lee-Huang, S., P.L. Huang, P.L. Nara, H.C. Chen, H.F. Kung, P. Huang, H.I. Huang, and P.L. Huang. 1990. A new inhibitor of HIV-1 infection and replication. FEBS Lett. 272:12-18.

Levi, A., C.E. Thomas, M. Newman, O.U.K. Reddy, X. Zhang, and Y. Xu. 2004. ISSR and AFLP markers differ among American watermelon cultivars with limited genetic diversity. J. Amer. Soc. Hort. Sci. 129:553-558.

Lubberstedt, T., A.E. Melchinger, C. Duble, M. Vuylsteke, and M. Kuiper. 2000. Relationships among early European maize inbreds: IV. Genetic diversity revealed with AFLP markers and comparison with RFLP, RAPD, and pedigree data. Crop Sci. 40:783-791.

Marr, K.L., X.Y. Mei, and N.K. Bhattarai. 2004. Allozyme, morphological and nutritional analysis bearing on the domestication of Momordica charantia (cucurbitaceae). Econ. Bot. 58:435-455

Milbourne, D., R. Meyer, J.E. Bradshaw, E. Baird, N. Bonar, J. Provan, W. Powell, and R. Waugh. 1997. Comparison of PCR-based marker systems for the analysis of genetic relationships in cultivated potato. Mol. Breed. 3:127-136.

Paris, H.S., N. Yonash, V. Portnoy, N. MozesDaube, G. Tzuri, and N. Katzir. 2003. Assessment of genetic relationships in Cucurbita pepo (cucurbitaceae) using DNA markers. Theor. Appl. Genet. 106:971-978.

Pavlicek, A., S. Hrda, and J. Flegr. 1999. FreeTree-Freeware program for construction of 
phylogenetic trees on the basis of distance data and bootstrap/jackknife analysis of the tree robustness. Application in the RAPD analysis of genus Frenkelia. Folia Biol. (Praha) 45:97-99.

Pejic, I., P. Ajmone-Marsan, M. Morgante, V. Kozumplick, P. Castiglioni, G. Taramino, and M. Motto. 1998. Comparative analysis of genetic similarity among maize inbred lines detected by RFLPs, RAPDs, SSRs, and AFLPs. Theor. Appl. Genet. 97:1248-1255.

Powell, W., M. Morgante, C. Andre, M. Hanafe, J. Vogel, S.V. Tingey, and A. Rafalski. 1996. The comparison of RFLP, RAPD, AFLP and SSR (microsatellite) markers for germplasm analysis. Mol. Breed. 2:225-238.

Prevost, A. and M.J. Wilkinson. 1999. A new system of comparing PCR primers applied to ISSR fingerprinting of potato cultivars. Theor. Appl. Genet. 98:107-112.

Reyes, M.E.C., B.H. Gildemacher, and G.J. Jansen. 1994. Momordica L., p. 206-210. In: J.S. Siemonsma and K. Piluek (eds.). Plant resources of south-east Asia-Vegetables. Pudoc Scientific Publishers, Wageningen, The Netherlands.

Robinson, R.W. and D.S. Decker-Walters. 1999. Cucurbits. CAB International, Wallingford, Oxford, UK, p. 240.

Rohlf, F.J. 1993. NTSYS-pc Numerical Taxonomy and Multivariate Analysis System. Version 2.0. Exeter Publications, New York.
Russell, J.R., J.D. Fuller, M. Macaulay, B.G. Hatz, A. Jahoor, W. Powell, and R. Waugh. 1997. Direct comparison of levels of genetic variation among barley accessions detected by RFLPs, SSRs, and RAPDs. Theor. Appl. Genet. 95:714-722

Singh, A.K., T.K. Behera, D. Chandel, P. Sharma, and N.K. Singh. 2007. Assessing genetic relationships among bitter gourd (Momordica charantia L.) accessions using inter simple sequence repeat (ISSR) markers. J. Hort. Sci. Biotechnol. 82:217-222.

Smith, J.S.C., E.C.L. Chin, H. Shu, O.S. Smith, S.J. Wall, M.L. Senior, S.E. Mitchell, S. Kresovich, and J. Ziegle. 1997. An evaluation of the utility of SSR loci as molecular markers in maize (Zea mays L.): Comparisons with data from RFLPs and pedigree. Theor. Appl. Genet. 95: 163-173.

Staub, J.E. and J. Bacher. 1997. Cucumber as a processed vegetable. In: Processing vegetables: Science and Technology IV. Technomic Publishing Co., Inc., Lancaster, PA.

Staub, J.E., S.M. Chung, and G. Fazio. 2005. Conformity and genetic relatedness estimation in crop species having a narrow genetic base: The case of cucumber (Cucumis sativus L.). Plant Breed. 124:44-53.

Staub, J.E., Y. Danin-Poleg, G. Fazio, T. Horjeshi, N. Reis, and N. Katzir. 2000. Comparative analysis of cultivated melon groups (Cucumis melo L.) using random amplified polymorphic
DNA and simple sequence repeat markers. Euphytica 115:225-241.

Staub, J.E., F. Serquen, and M. Gupta. 1996. Genetic markers, map construction and their application in plant breeding. HortScience 31:729-741.

Sun, Z., R.L. Lower, S.M. Chung, and J.E. Staub. 2006. Identification and comparative analysis of quantitative trait loci (QTL) associated with parthenocarpy in processing cucumber. Plant. Breed. 125:281-287.

Vos, P., R. Hogers, M. Bleeker, M. Reijans, T. Van De Le, M. Hornes, A. Frijters, J. Pot, J. Peleman, M. Kuiper, and M. Zabeau. 1995. AFLP: A new technique for DNA fingerprinting. Nucleic Acids Res. 23:4407-4414.

Wang, Y.H., R.A. Dean, and T. Joobeur. 2006. Genetic mapping and molecular breeding in cucurbits. Plant Breeding Reviews 27:213244.

Yang, S.L. and T.W. Walters. 1992. Ethnobotany and the economic role of the cucurbitaceae of China. Econ. Bot. 46:349-367.

Yashiro, K., H. Iwata, Y. Akashi, K. Tomita, M. Kuzuya, Y. Tsumura, and K. Kato. 2005. Genetic relationship among east and south Asian melon (Cucumis melo L.) revealed by AFLP analysis. Breed. Sci. 55:197-206.

Yeh, G.Y., D.M. Eisenber, T.J. Kaptchuk, and R.S. Phillips. 2003. Systematic review of herbs and dietary supplements for glycemic control in diabetes. Diabetes Care 26:1277-1294. 